\title{
AVALIAÇÃO DA PERCEPÇÃO DA ARBORIZAÇÃO URBANA EM FORTALEZA.
}

Carlos Germano Ferreira Costa $^{1}$, Ricardo Figueiredo Bezerra ${ }^{2}$, George Satander Sa Freire ${ }^{3}$

\section{RESUMO}

O presente estudo objetivou avaliar a percepção dos alunos de graduação da Universidade Federal do Ceará (UFC), que frequentam o campus do Pici, com relação à Arborização Urbana existente na cidade de Fortaleza em comparação com a área da UFC, bem como os benefícios e prejuízos que esta arborização traz. Para tanto foi aplicado um questionário a 274 estudantes. Os resultados obtidos mostram o perfil da percepção da Arborização Urbana desses alunos, sendo a análise feita a partir das variáveis gênero, idade, curso e bairro de moradia. Os resultados apontam que, na percepção da maioria o nível da arborização de Fortaleza e do local de residência é considerado regular, em contrapartida o nível da arborização do campus do Pici é considerado de bom a muito bom. Foram aplicados testes estatísticos (qui-quadrado) aos dados sendo observado alguns resultados significantes entre o curso e o nível percebido da arborização.

Palavras-chave: Áreas Verdes Urbanas; Educação Ambiental; Percepção Ambiental.

\section{EVALUATION OF URBAN GREEN AREAS PERCEPTION IN FORTALEZA.}

\section{ABSTRACT}

The present study aimed to evaluate the perception of undergraduate students of the Universidade Federal do Ceará (UFC), who attend the Pici's campus with respect to urban trees existing in the city of Fortaleza in comparison with Urban Trees in the area of the (UFC), as well as the benefits and disadvantages that urban trees brings. To do so a questionnaire was administered to 274 students. The results show the perception of these students regarding uban trees, and the analysis based on the variables gender, age, year and district of residence. The results show that the perception of the level of afforestation in Fortaleza and in the place of residence is considered regular, however the level of greening the Pici's campus is considered good to very good. We applied statistical tests (chi-square) to the data, being observed some significant findings between the course and the perceived level of afforestation.

Keywords: Urban Green Areas, Environmental Education, Environmental Perception.

\footnotetext{
${ }^{1}$ Doutorando em Desenvolvimento e Meio Ambiente,DDMA-PRODEMA,Mestre em Ecologia e Recursos Naturais, Universidade Federal do Ceará, Centro de Ciências, Bloco 902, Campus do Pici - Fortaleza, Ceará, Caixa Postal 67011, carlosgermanopj@gmail.com

2 Professor Associado do Departamento de Arquitetura e Urbanismo da Universidade Federal do Ceará. Ph.D em planejamento urbano pela Universidade de Nottingham (UK) e mestre em arquitetura paisagística pela Universidade do Arizona (EUA) - Universidade Federal do Ceará, Centro de Ciências, Bloco 902, Campus do Pici - Fortaleza, Ceará, Caixa Postal 67011. E-mail: rbezerra@arquitetura.ufc.br

${ }^{3}$ Professor associado III da Universidade Federal do Ceará.Doutor em Geologie - Universite de Nantes e Mestre em Geociências, Universidade Federal do Ceará, Centro de Ciências, Bloco 902, Campus do Pici - Fortaleza, Ceará, Caixa Postal 67011, freire@ufc.br

${ }^{4}$ recebido em 25.05 .12 e aceito para publicação em 15.12 .2013
} 
A análise de percepção da população tem sido utilizada como meio de medir o grau de satisfação da população, em várias cidades no Brasil e no mundo (OKAMOTO, 2002). Essa avaliação, geralmente, realiza-se através da aplicação de questionários. Tal ferramenta de pesquisa, no entanto, tem sido pouco explorada para esse fim em Fortaleza-CE, cidade que conta com poucas áreas verdes, as quais sofrem forte especulação imobiliária e descaso por parte da população e do poder público.

Existem várias definições para Arborização Urbana, dentre elas considera-se Arborização Urbana o conjunto de exemplares arbóreos de porte e forma compatível com o espaço, e que não ofereça problemas físicos ou fitossanitários (SANTOS; TEIXEIRA, 2001).

Segundo Sanchotene (1994), entende-se por Arborização Urbana o conjunto de terras públicas e privadas com vegetação predominantemente arbórea de uma cidade. Também pode ser definida como o conjunto da vegetação arbórea natural ou cultivada que uma cidade apresenta. Esta vegetação está representada em áreas particulares, parques, praças, vias públicas e em outras áreas verdes complementares.

A árvore é o elemento fundamental no desenho urbano, na medida em que define e estrutura o espaço. Tem influência decisiva na qualidade de vida nas cidades e, portanto na saúde das populações. Cabe mencionar que "as árvores representam valores culturais da memória histórica das cidades", como é o caso, por exemplo, das famosas mangueiras de Belém do Pará (SANCHOTENE, 1989).

Neste sentido a França foi uma das maiores influências para a cidade de Fortaleza, imprimindo seu nome na arte e cultura, tendo irradiado um dos períodos mais ricos da história ocidental: a Belle Époque, cujos reflexos foram sentidos em Fortaleza do período que vai do final do século XIX até o começo do século XX, época em que a Europa foi varrida por um vento de euforia e de esperança diante da vida. Era um tempo de paz e de relativo bem-estar, que durou até 1914 quando explodiu a I Guerra Mundial, da qual a França participou, assim como no segundo conflito (1939-1945). Embora na Europa, essa fase tenha terminado com a Primeira Guerra Mundial, em Fortaleza o período se estendeu até os anos 1920 (PONTE, 2001).

Entretanto, segundo Marques (2005), Fortaleza enfrenta há muitos anos, sérios problemas na gestão e execução da arborização urbana, sendo hoje uma cidade mal arborizada. Há poucas árvores e grande parte delas está mutilada por podas incorretas. A cidade também enfrenta o problema da pouca biodiversidade arbórea. Estudos realizados por Moro e Westerkamp (2011), mostraram que, em alguns bairros de Fortaleza, mais da metade das árvores pertencem a uma única espécie.

Esse tipo de arborização é ecologicamente incorreto, pois limita a diversidade de opções alimentares para a fauna, além de aumentar as possibilidades de que doenças e pragas se espalhem rapidamente entre as árvores. Desta forma, deve-se evitar a arborização de um bairro ou cidade com um a única espécie (GRAZIANO, 1994). O desafio de planejar a arborização de Fortaleza é extenso, sendo necessário enfocar os problemas mais graves para serem combatidos (MORO; WESTERKAMP, 2011).

A administração e manejo da arborização devem ser exercidos por órgãos públicos ambientais, órgãos executivos por excelência, porém, se torna Carlos Germano Ferreira Costa et al 
necessário, para a realização de arborização urbana de maneira adequada, a participação de universidades, instituições de pesquisa e concessionárias de serviços urbanos, e da participação da população. Um primeiro passo. Que se faz necessário está em avaliar a percepção da população sobre a questão da Arborização Urbana e a importância que o tema exige.
Nesse sentido o presente estudo objetiva avaliar a percepção ambiental dos alunos de graduação da Universidade federal do Ceará (UFC), que frequentam o campus do Pici, com relação à arborização urbana existente na cidade de Fortaleza em comparação com a área da UFC, bem como os benefícios e prejuízos que arborização traz.

\section{MATERIAIS E MÉTODOS}

\section{Caracterização da cidade de Fortaleza}

A cidade de Fortaleza localiza-se sobre suaves ondulações litorâneas a uma altitude média de 21 metros, nas coordenadas de $-03^{\circ} 46^{\prime} 06^{\prime \prime}{ }^{\circ} \mathrm{S}$ e $38^{\circ}$ 31' 36" W. Está localizada no litoral norte do Estado do Ceará cobrindo uma área aproximada de $300 \mathrm{~km} 2$ com uma população de cerca de 2.452.185 habitantes, sendo, hoje, a quinta maior cidade brasileira. Apresenta índice de urbanização de $100 \%$ com densidade demográfica em torno de 7.786,52 hab $/ \mathrm{Km}^{2}$, concentrados numa área de $314,927 \mathrm{Km}^{2}$. Administrativamente, Fortaleza está dividida em seis Secretarias Regionais. (IPECE; 2012; IBGE, 2013). Segundo dados da Secretaria de Urbanismo e Meio Ambiente - SEUMA (2013), os resultados dos programas de revitalização de Arborização urbana podem ser definidos como insuficientes, com a exceção do mapeamento

\section{A Universidade Federal do Ceará e o campus do Pici}

\section{A Universidade Federal do Ceará (UFC)} ocupa uma área total de 233 ha, dividida em três campi: Benfica, Porangabussu e Pici. Localizado na área da Secretaria Regional III, em bairro de mesmo nome, o campus do Pici, ambiente utilizado para este estudo, equivale a 212 hectares e abriga os Centros de Ciências, Ciências Agrárias e arbóreo de Fortaleza e plantio e distribuição de 6.500 mudas para ações de Educação Ambiental, apontando como desafios a elaboração de um Plano de Urbanismo, Meio Ambiente e Controle Urbano para Fortaleza, ressaltando a importância de formular um Plano de Monitoramento Estratégico que inclua temas tais como: coleta seletiva, educação ambiental, política verde para a cidade e adoção de parques.

O clima é predominantemente equatorial e intertropical, favorecido por suave e constante brisa vinda do mar, que proporciona uma temperatura média anual de $27^{\circ} \mathrm{C}$. As chuvas são mais freqüentes nos meses de janeiro a julho, com média anual de aproximadamente $1.600 \mathrm{~mm}$ (FUNCEME, 2013).

Tecnologia; as Pró-Reitorias de Graduação e de Pesquisa e Pós-Graduação; a Biblioteca Universitária, núcleos e laboratórios diversos, além do setor esportivo (UFC, 2013) 
A percepção ambiental acerca da condição atual da arborização urbana da cidade de Fortaleza (Ceará), pelos alunos de graduação da UFC, no campus do Pici, foi medida através de questionário realizado entre os dias 15 e 17 de maio de 2007 com 274 estudantes da instituição. Os locais utilizados para a realização das entrevistas foram a Biblioteca Central de Ciências e Tecnologia, cantinas dos departamentos e dependências do Restaurante Universitário.

O questionário abordou questões referentes ao Perfil dos entrevistados e sobre a percepção destes sobre a Arborização Urbana. As primeiras quatro perguntas eram relativas ao perfil do entrevistado: gênero, idade, centro do curso e bairro de residência. As sete perguntas seguintes eram de avaliação sobre a percepção do entrevistado sem relação à Arborização Urbana, considerando as escalas em nível de cidade, de bairro, de quarteirão de residência e do campus do Pici, em particular. Essas questões eram apresentadas numa escala de 0 a 10 , sendo para efeito de computação dos dados, transformadas em variável ordinal (Tabela 1). Havia duas perguntas, com dez opções elencadas cada, relativas às vantagens e desvantagens da Arborização Urbana, sendo solicitado ao sujeito à escolha de somente uma dessas. Opinião sobre o interesse em participar de ações voluntárias de plantio e manutenção de árvores. E, finalmente, os entrevistados foram perguntados sobre o interesse em participar de ações voluntárias de plantio e manutenção de árvores em áreas públicas.

Tabela 1. Parâmetros de avaliação.

\begin{tabular}{ll}
\hline Notas & Avaliação \\
\hline 0 a 1 & Muito ruim \\
2 a 3 & Ruim \\
4 a 6 & Regular \\
7 a 8 & Bom \\
9 a 10 & Muito Bom \\
\hline
\end{tabular}

O tratamento estatístico descritivo dos resultados foram obtidos utilizando o software SPSS for Windows release 7.5.1 Standard Version.

A percepção da arborização urbana pelos sujeitos desta pesquisa foi medida em diferentes escalas urbanas. Partindo da escala municipal, as questões delimitaram, em seguida, a escala do bairro, depois da rua e por último do quarteirão de residência do entrevistado, levando em conta apenas as árvores existentes no entorno dos domicílios. Desconsiderando as que ficam, por exemplo, nos jardins internos. Em seguida, foi feita uma avaliação da percepção da arborização do campus do Pici, também seguindo uma seqüência escalar: primeiro o campus como um todo, depois a área do centro e por último o entorno imediato do curso ou departamento. 
Os resultados estão apresentados da seguinte maneira. Primeiramente com um perfil dos entrevistados e em seguida são mostrados os

\section{Perfil dos entrevistados}

Dos 274 entrevistados, 54\% (148 pessoas) eram do sexo masculino e os $46 \%$ restantes (126 pessoas) do sexo feminino. Em relação à idade dos entrevistados, esta variou de 17 a 60 anos, com idade média de 21,0 anos. Cerca de metade dos entrevistados tinha entre 21 e 25 anos de idade. Aproximadamente oito em cada dez entrevistados situaram-se na faixa de idade entre 17 e 25 anos.

\section{Percepção da Arborização Urbana em Fortaleza}

Os resultados permitiram perceber que os entrevistados tendem a considerar o nível de arborização de Fortaleza como regular, onde, dos 274 alunos, aproximadamente $2 / 3 \quad(61,7 \%)$ consideram a arborização urbana de Fortaleza neste nível. Somente um em cada dez $(9,1 \%)$ considera a arborização de Fortaleza no nível ruim e muito ruim $(7,3 \%$, e $1,8 \%$ respectivamente). Os demais entrevistados, ou seja, um pouco menos de $1 / 3$ deles avaliam a situação da arborização urbana de Fortaleza positivamente, ou seja, no nível bom ou muito bom $(28,8 \%$, e $0,4 \%$ muito bom respectivamente). Observa-se, com isso, uma resultados quantitativos do estudo, bem como as relações significativas que foram encontradas através de aplicação de teste de "qui-quadrado".
Foram entrevistados acadêmicos de graduação pertencentes a cursos de quatro centros, sendo a maioria deles do Centro de Ciências Agrárias. É importante notar que um pequeno percentual $(2,2 \%$ do total) era de alunos da Faculdade de Farmácia, Odontologia e Enfermagem, que tinham aulas no campus do Pici.

elevada concentração de avaliações no nível regular e proporcionalmente maior percentual de avaliações positivas que negativas para este quesito. Com base nesse resultado, apesar das deficiências observadas na Arborização Urbana de Fortaleza, verifica-se uma maior aprovação das áreas verdes presentes na cidade (Figura 1). Em outras pesquisas, houve uma tendência por parte da população em aprovar a Arborização Urbana local, por exemplo, Malavasi e Malavasi (2001), afirmam que para $56 \%$ da população urbana da cidade de Mal. Cândido Rondon havia o reconhecimento de alguma vegetação, assim como a população neste estudo.

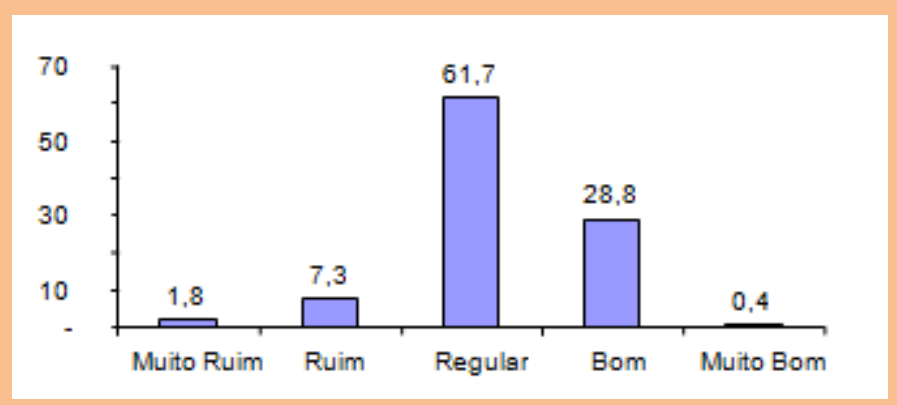

Figura 1. Percepção da Arborização Urbana - o município de Fortaleza em Maio de 2007. AVALIAÇÃO DA PERCEPÇÃO DA ARBORIZAÇÃo URBANA EM FORTALEZA. 


\section{Percepção da Arborização Urbana no bairro de residência do entrevistado}

Quando abordados sobre a arborização urbana no bairro onde moram, observou-se novamente um maior número das avaliações de nível regular. No entanto, neste caso, a distribuição é mais uniforme, notando-se um decréscimo no nível regular e um acréscimo nos níveis muito ruim, ruim, e muito bom. Novamente as avaliações positivas superam as negativas. Quatro em cada dez entrevistados avaliam a arborização urbana do próprio bairro positivamente - $28,8 \%$ considerando no nível bom,e $8,4 \%$ no nível muito bom - lembrando, que na escala da cidade este número era de três em cada dez indivíduos, enquanto as avaliações negativas (13,9\% ruim, e 5,5,\% muito ruim) restringem-se a cerca de duas pessoas em cada dez.
Observa-se novamente a tendência a avaliar a arborização urbana nos bairros sob uma ótica mais positiva, porém, é preciso notar que a avaliação negativa apresentou um ligeiro acréscimo em relação à avaliação anterior. Este resultado, possivelmente, joga luz sobre a dificuldade em avaliar com exatidão extensas áreas geográficas. A capacidade de percepção do individuo, é possivelmente afetada e sofre limitações de ordem espacial, uma vez que com a redução da área a ser avaliada, percebe-se uma avaliação mais crítica, com maior identificação de falhas, ocasionando a elevação das respostas negativas (Figura 2).

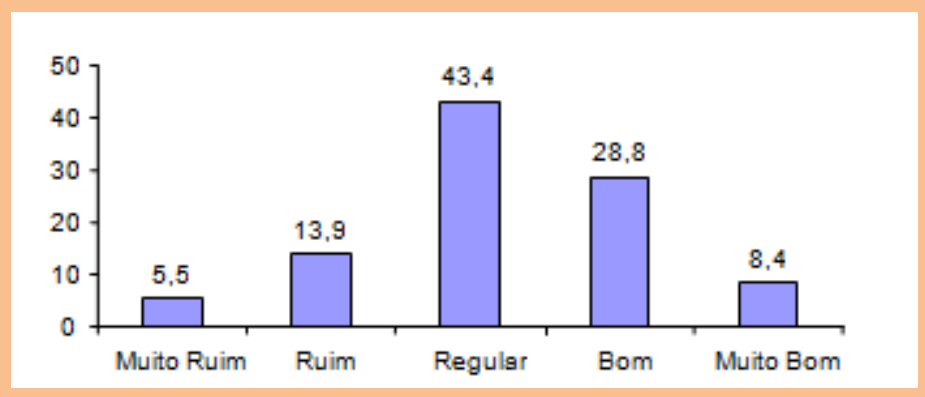

Figura 2. Percepção da Arborização Urbana - os bairros do município de Fortaleza em Maio de 2007.

\section{Percepção da arborização urbana da rua de residência do entrevistado}

Já no que diz respeito à avaliação da arborização urbana da rua onde reside o entrevistado, a tendência de equilíbrio entre as avaliações positivas e negativas se alteram. É percebida uma avaliação mais crítica em relação à percepção da Arborização Urbana, com a redução da área a ser avaliada, ou seja, a rua. Observa-se a elevação das avaliações negativas, e forte redução das avaliações de nível regular, quando comparadas com as avaliações de percepção da Arborização Urbana para o município e dos bairros do município de Fortaleza.
Neste nível, mais de $30 \%$ dos entrevistados avaliam a arborização urbana negativamente $(21,5 \%$ como ruim, e $12 \%$ como muito ruim). Entretanto, nesse npivel observa-se uma divisão semelhante de avaliações. Cerca de 30\% de entrevistados continua a considerar a Arborização Urbana nas ruas positivamente (23\% bom, e $8 \%$ muito bom), percentual mantido quando comparado às avaliações da percepção da Arborização Urbana nos bairros ( $28,8 \%$ bom, e $8,4 \%$ muito bom), porém, em relação à avaliação a nível de município 
apresenta uma expressiva elevação, passando de $0,4 \%$ de avaliação "muito boa", para $8,0 \%$ ao avaliar o bairro, e $8,4 \%$ ao avaliar a escala da rua . Percebe-se, nesta situação, uma redução visível no nível de avaliação regular, em comparação com as escalas anteriormente consideradas. Uma possível explicação para esses resultados seria supor que os entrevistados têm a habilidade de perceber falhas e/ou vantagens pontuais na arborização e avaliar de modo mais crítico a arborização urbana de pequenas áreas, em detrimento daquelas de maior extensão, porém não fica claro os motivos que mantêm a avaliação "muito boa" nos mesmos níveis em todas as escalas, e a elevação das avaliações positivas, uma vez que seria esperado a percepção mais acentuada de falhas na Arborização Urbana (Figura 3).

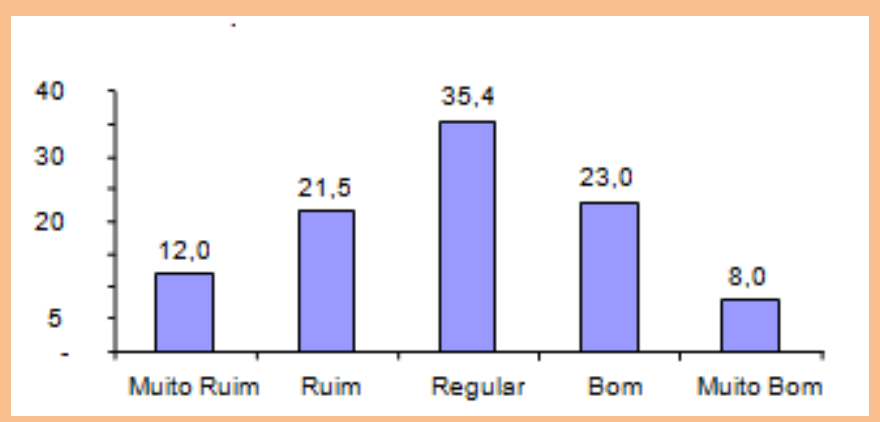

Figura 3. Percepção da Arborização Urbana - as ruas do município de Fortaleza em Maio de 2007.

\section{Percepção da arborização urbana na quadra de residência do entrevistado}

Com relação às avaliações considerando a arborização nos quarteirões onde moram os entrevistados, nota-se que é bastante semelhante aos resultados encontrados na escala da rua. Novamente, houve uma tendência de aproximação entre as avaliações positivas e negativas, com redução das avaliações no nível negativo "muito ruim", passando de $21,5 \%$ para $16, \& \%$ em relação à escala da rua, e mantendo-se os mesmos níveis de percepção nas avaliações "muito ruim" $12 \%$, "bom $23 \%$ e "muito bom", ao redor de 8,0\% (Figura 4).

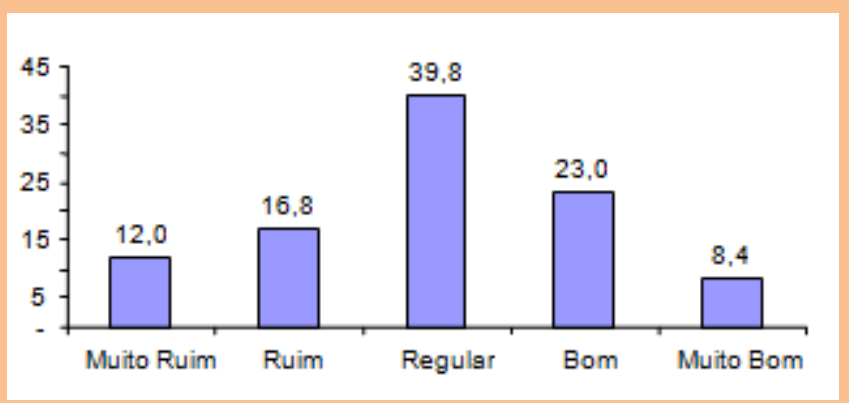

Figura 4. Percepção da Arborização Urbana - os quarteirões do município de Fortaleza em Maio de 2007.

A partir dos resultados alcançados nas escalas urbanas descritas acima, não é possível definir, a princípio, nenhuma tendência além da avaliação regular, para todos os casos, variando a mesma de
$35,4 \%$ na escala da rua a $61,7 \%$ na escala da cidade, e certa manutenção dos níveis de avaliações positivas acerca da Arborização Urbana no 
município de Fortaleza, em torno de $30 \%$ de

\section{Percepção da arborização urbana no campus do Pici}

Por sua vez, a avaliação da arborização urbana do campus do Pici apresenta um perfil bem diferente daquele observado para as áreas anteriormente avaliadas, confirmando as expectativas ao escolher esta área como referência. Percebe-se um posicionamento claramente positivo em relação à avaliação da arborização do campus do Pici com quase nove em cada dez $(87,2 \%)$ dos entrevistados aprovação.

optando por avaliá-la nos níveis mais elevados respectivamente entre os níveis bom $(36,1 \%)$ e muito bom $(51,1 \%)$, sendo este último mencionado por mais da metade dos entrevistados. Resultado que permite afirmar que há uma forte aprovação da arborização presente no campus do Pici, por parte desta população (Figura 5).

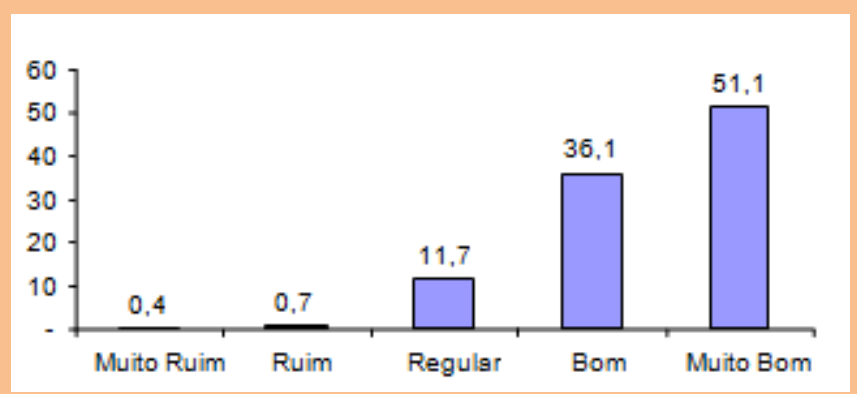

Figura 5. Percepção da Arborização Urbana - o campus do Pici em maio de 2007.

\section{Percepção da Arborização Urbana no entorno dos departamentos do campus do Pici.}

$\mathrm{Na}$ avaliação do nível da arborização urbana no entorno dos departamentos dos cursos pelos acadêmicos, novamente, como esperado, percebe-se a forte aprovação por parte dos mesmos, 43,4\% afirmam ser "bom", e 37,2\% "muito bom", perfazendo $82,6 \%$ do total. Vale ressaltar, porém, isto se dá num nível ligeiramente menor que o notado para o campus como um todo. As avaliações negativas, apesar de uma ligeira elevação, registraram em torno de $5 \%$ das escolhas. Neste momento $14,6 \%$ entrevistados optaram por avaliar a arborização nos departamentos como regular (Figura 6).

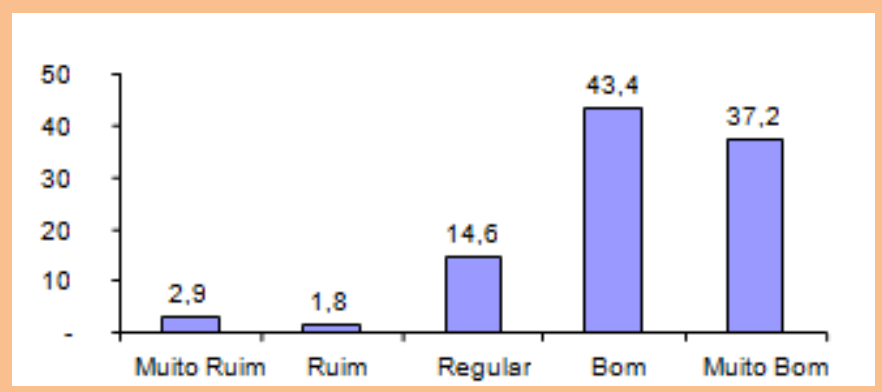

Figura 6. Percepção da Arborização Urbana - em torno do departamento do campus do Pici em Maio de 2007. 
Provavelmente, os motivos que levam os entrevistados a avaliar o em torno dos seus departamentos menos positivamente, em relação à arborização do campus como um todo, seja a maior familiaridade com a arborização destas áreas frequentemente usadas. Pode-se supor que, a hipótese apresentada para explicar o padrão de diferenças progressivas na avaliação feita para as escalas anteriores (cidade, bairro e rua), se repete para o campus como um todo. Ou seja, quanto menor a escala, maior a tendência em avaliar mais criticamente, seja para o lado positivo ou negativo, outro fator a ser considerado seria que esses resultados refletem diferenças temporais no processo de urbanização e, consequentemente, na arborização da Universidade e da cidade onde as ruas mais "antigas" possuem uma arborização conspícua e de maior porte do que as ruas recentemente urbanizadas.

\section{Percepção do conforto ambiental na cidade de Fortaleza.}

Pouco mais da metade dos entrevistados, 54,7\% destes, avalia o conforto ambiental de Fortaleza como regular. No entanto, nota-se uma tendência para as avaliações positivas (bom e muito bom). Cerca de três pessoas em cada dez, 27,7\%, respectivamente $26,6 \%$ como "bom", e $11, \%$ como "muito bom", avaliaram o conforto ambiental, positivamente, enquanto pouco menos de duas em cada dez o avaliaram negativamente, $17,5 \%$, ou seja, $15,3 \%$ como "ruim", e 2,2\% como "muito ruim" (Figura 7).

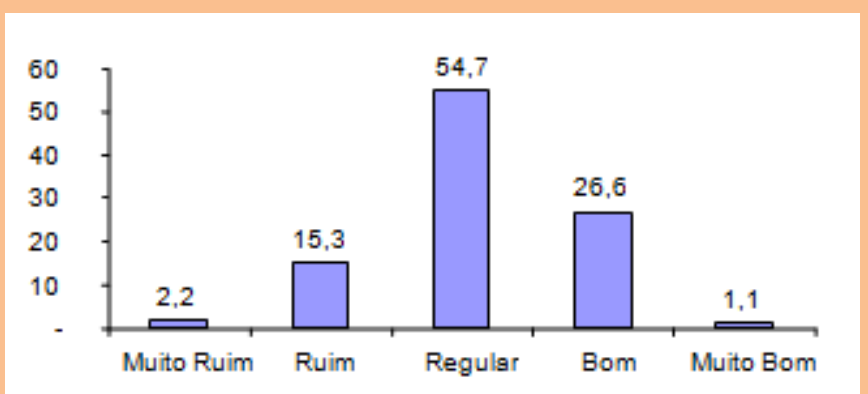

Figura 7. Percepção do conforto ambiental no município de Fortaleza em Maio de 2007.

Este resultado contrasta, com a baixa qualidade e reduzido nível de arborização urbana em Fortaleza, comum na maioria dos municípios brasileiros, que cresceram sem planejamento e sem a criação de ambientes que contribuíssem com o bem-estar dos cidadãos, sejam praças, parques urbanos ou a arborização urbana, uma vez que planejar a arborização é indispensável para o desenvolvimento urbano, para não trazer prejuízos para o meio ambiente e, considerando que a arborização é fator determinante da salubridade ambiental, por ter influência direta sobre o bem estar do homem, em virtude dos múltiplos benefícios que proporciona ao meio, em que além de contribuir à estabilização climática (DANTAS, 2004).

O que se vê são cidades com calçadas concretadas, sem árvores, gerando um desequilíbrio climático, aumentando a temperatura nos centros urbanos, 
resultando numa paisagem árida, que não propicia uma condição saudável de vida, desta maneira, a vida na cidade está se tornando mais difícil e, em alguns casos, até insuportável. O habitante da cidade, a cada minuto que passa, envolve-se cada vez mais com os problemas ligados ao progresso e

\section{Percepção das vantagens da arborização urbana.}

Quando perguntado aos entrevistados sobre as vantagens que a arborização urbana proporciona ao meio ambiente urbano, a partir do seu ponto de vista, pouco mais da metade $(53,6 \%)$ afirmou que o principal benefício da arborização urbana relacionase com o controle da temperatura. Essa opção foi seguida, com uma grande distância, pelas opções de tornar a paisagem urbana mais agradável, com aproximadamente dois em cada dez $(17,9 \%)$ entrevistados optando por esta alternativa, e apenas cerca de 10\% destes, escolhendo controle da poluição do ar como um benefício da arborização urbana. Vale ressaltar que nenhum dos ao desenvolvimento e se esquece de usufruir um pouco do bom que a natureza proporciona. Assim sendo, envolve-se cada vez mais no meio físico por ele criado, gerando hipertensões e neuroses que se agravam em ritmo acelerado (SANTIAGO, 1980).

entrevistados relacionou o controle da erosão do solo $(0 \%)$, e nem valorização de bens e imóveis $(0 \%)$ como benefícios proporcionados pela arborização urbana, e apenas uma fração insignificante relacionou a arborização urbana com o controle da poluição sonora ( $0,4 \%$ ) (Figura 8$)$.

Segundo Malavasi e Malavasi (2001), em sua pesquisa, do total de entrevistados, $92 \%$ percebem alguma vantagem da presença da arborização sendo que os benefícios relacionados com o conforto térmico foi o item mais lembrado, e $75 \%$ dos entrevistados declararam sua colaboração na manutenção da arborização urbana.

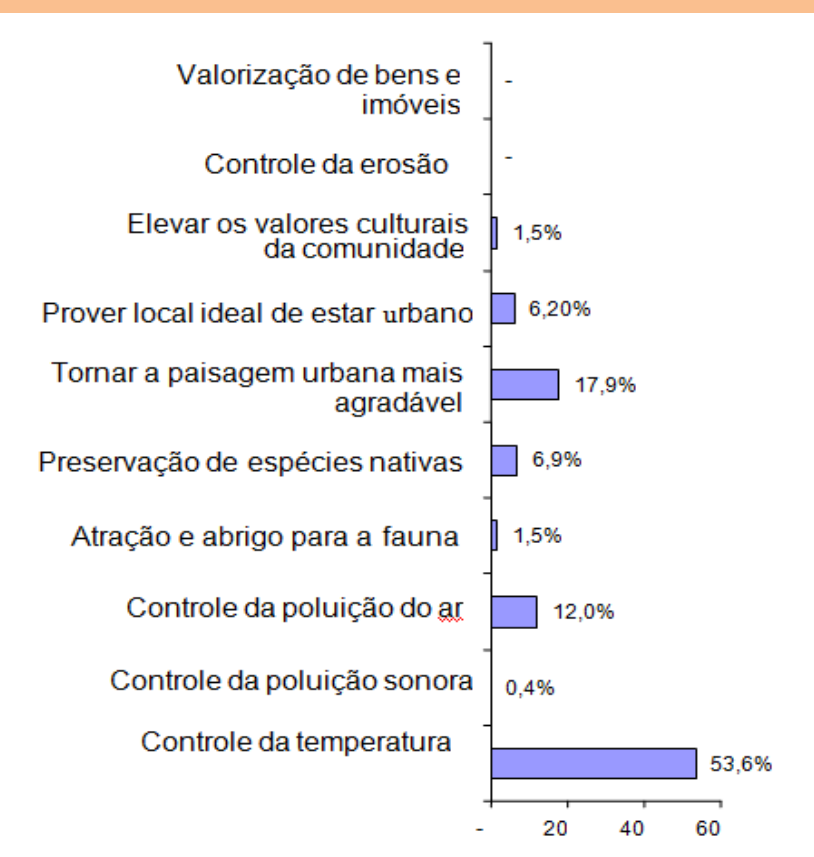

Figura 8. Percepção das vantagens da Arborização Urbana no município de Fortaleza em maio de 2007. 
Os fatores que levam os entrevistados a ignorar o controle da erosão do solo, e a valorização de bens e imóveis como benefícios, não são percebidos nas entrevistas, não sendo possível explicar com exatidão estas razões, poder-se-ia inferir a falta de conhecimento técnico em relação ao controle da erosão, porém está explicação não seria completa uma vez que se constata a presença de acadêmicos de Engenharias e Biologia por exemplo. É possível supor que a não citação do controle da erosão do solo como benefício da arborização urbana, possa ser devida ao elevado percentual de

\section{Percepção das desvantagens da arborização urbana.}

Por outro lado, quando questionados sobre as desvantagens que a arborização urbana acarreta na cidade, as respostas mostraram-se equilibradas, sendo lideradas e divididas entre três alternativas. São elas: medo do desabamento da árvore $(16,4 \%)$, perigo da queda de frutos $(16,4 \%)$ e destruição dos pavimentos pelas raízes $16,4 \%$ ). Essas três impermeabilização do solo na cidade, e a ausência de morros e encostas na cidade de Fortaleza, ou seja, a não existência de problemas relacionados a deslizamento de terras, comuns em cidades como Rio, São Paulo e Salvador por exemplo.

Por sua vez, ao não citar valorização de bens e imóveis, como benefício proporcionado pela arborização urbana, poder-se-ia afirmar que esta população desconhece as vantagens que a realização de projetos paisagísticos proporciona na valorização do espaço urbano e da arquitetura das construções. alternativas totalizam quase metade das respostas dadas $(49,2 \%)$, seguidas pelas opções preocupação com os estragos causados pelas raízes nas tubulações subterrâneas $(11,7 \%)$ e dos estragos causados pelos galhos na fiação aérea citada por $11,7 \%$ dos entrevistados (Figura 9).

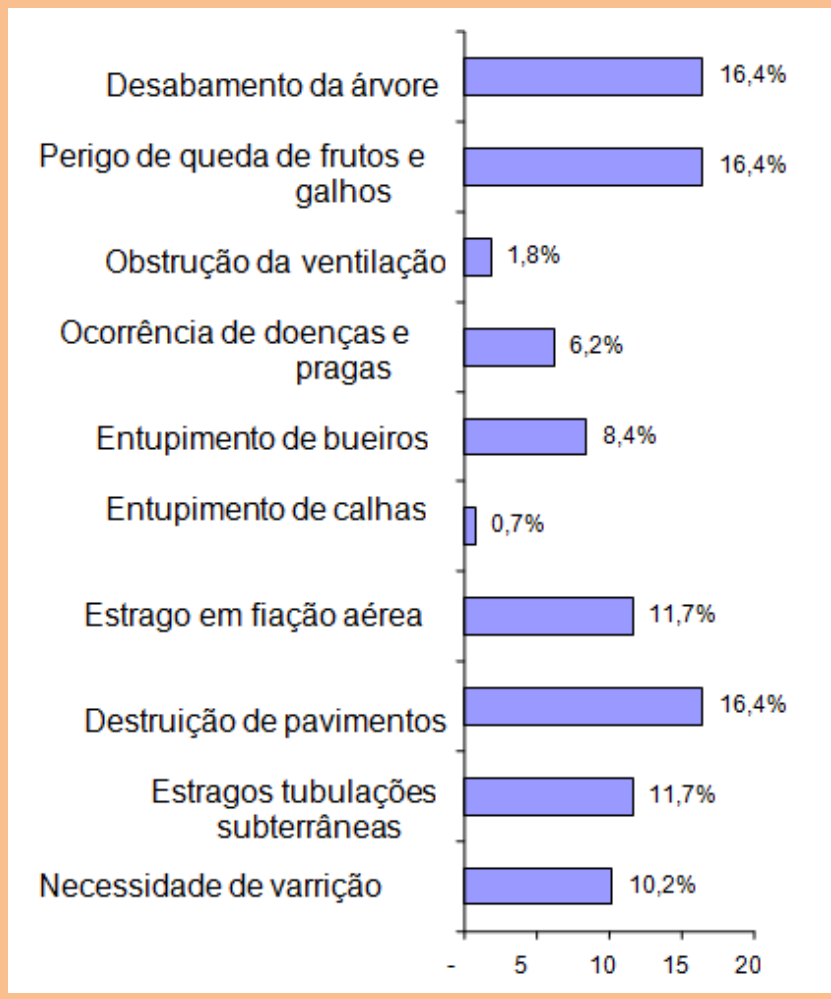

Figura 9. Percepção das desvantagens da Arborização Urbana no município de Fortaleza em maio de 2007

AVALIAÇÃO DA PERCEPÇÃO DA ARBORIZAÇÃO URBANA EM FORTALEZA. 
Enquanto a avaliação dos aspectos positivos da arborização urbana foi concentrado em uma alternativa - mais da metade $(53,6 \%)$ afirmou que o principal benefício da arborização urbana relacionase com o controle da temperatura - os aspectos negativos são mais lembrados, e distribuídos uniformemente dentre as opções apresentadas medo do desabamento da árvore $(16,4 \%)$, perigo da queda de frutos $(16,4 \%)$ e destruição dos pavimentos pelas raízes $16,4 \%$ ), totalizando $49,2 \%$ dos entrevistados. Segundo Oliveira (1996), os parâmetros utilizados, pelos indivíduos, para a avaliação da percepção, nesse caso, da Arborização Urbana baseia-se, não somente, na observação e mensuração de variáveis biológicas, sendo admitidas que fatores sentimentais, psicológicos e estéticos são variáveis importantes (OLIVEIRA, 1996), levando a supor que os indivíduos entrevistados associam a Arborização Urbana a variáveis negativas, quando confrontados com as opções dadas.

Opinião sobre o interesse em participar de ações voluntárias de plantio e manutenção de árvores em áreas públicas.

No questionário foi perguntado aos entrevistados sobre ao interesse em participar de atividades voluntárias de plantio e manutenção de árvores na cidade. Os dados confirmam que a maioria da população entrevistada tem interesse em participar de ações relacionadas ao meio ambiente, na área de arborização urbana. Eles representam quase sete em cada dez entrevistados (Figura 10).

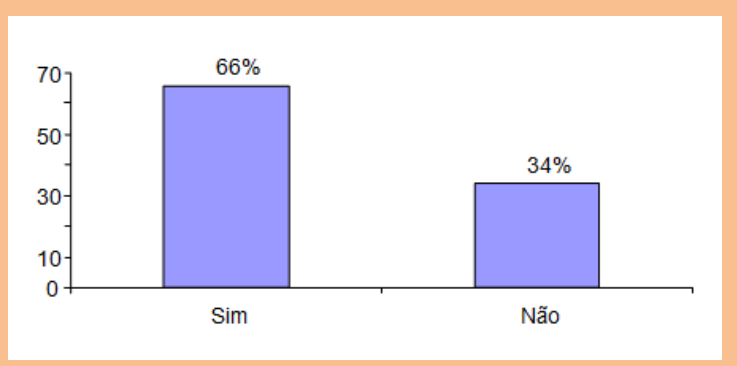

Figura 10. Interesse em participar de atividades voluntárias de plantio de árvores em áreas públicas.

Os dados obtidos nesta pesquisa confirmam pesquisas anteriores que reafirmam o interesse da população em participar de ações voluntárias relativas à Arborização Urbana. $\mathrm{Na}$ presente pesquisa os entrevistados foram indagados sobre o interesse em participar de atividades voluntárias de plantio de árvores em áreas públicas. Uma parcela expressiva dos entrevistados demonstrou-se favorável a tomar parte nesta atividade, $66 \%$ afirmaram interesse em participar de atividades voluntárias de plantio e manutenção de árvores em áreas públicas em Fortaleza. Malavasi e Malavasi (2001), ao entrevistar a população em munícipes rondonenses obtiveram respostas positivas de $91 \%$ dos entrevistados, ao se declararem propensos a contribuir anualmente com valores entre R\$ 1,00 e 


\section{ANÁLISE PRELIMINAR DOS RESULTADOS}

Cruzando algumas variáveis do estudo como a avaliação do nível de Arborização Urbana no município de Fortaleza, e nível da Arborização Urbana no campus do Pici com o local onde o acadêmico estuda foram observadas, através da aplicação de testes de "qui-quadrado", associações entre algumas delas. Optou-se por apresentá-las graficamente, ao invés do uso de tabelas, por uma questão de melhor visualização desses resultados.

\section{Avaliação da arborização urbana de Fortaleza versus o Centro onde estuda o entrevistado}

Observou-se que o Centro onde o entrevistado estuda influência no modo como este percebe a situação da arborização urbana. Nota-se que os alunos do Centro de Ciências Agrárias concentram suas avaliações no nível regular, enquanto os alunos do Centro de Tecnologia tendem a avaliar mais positivamente a arborização urbana de Fortaleza. $\mathrm{Na}$ população estudada somente os alunos do Centro de Ciências consideraram a arborização urbana de Fortaleza num nível muito bom. Uma possível explicação para este fato seria, em relação aos acadêmicos de do Centro de Ciências Agrárias, que estes majoritariamente acadêmicos do Curso de Engenharia Agronômica possam ter mais aulas práticas e de campo, e pela característica multidisciplinar do Curso tenham disciplinas ministradas em outros Centros dentro do campus do Pici, circulando por uma maior área desta forma desenvolvendo melhor percepção devida à maior circulação geográfica, comparado à acadêmicos de outros Centros, como por exemplo, os do Centro de Tecnologia, que geralmente tem aulas concentradas no próprio Centro. Aplicando-se o teste de "quiquadrado" obtém-se um nível de significância de 0,04, o que demonstra uma associação entre estas variáveis. A figura 11 mostra graficamente a associação.

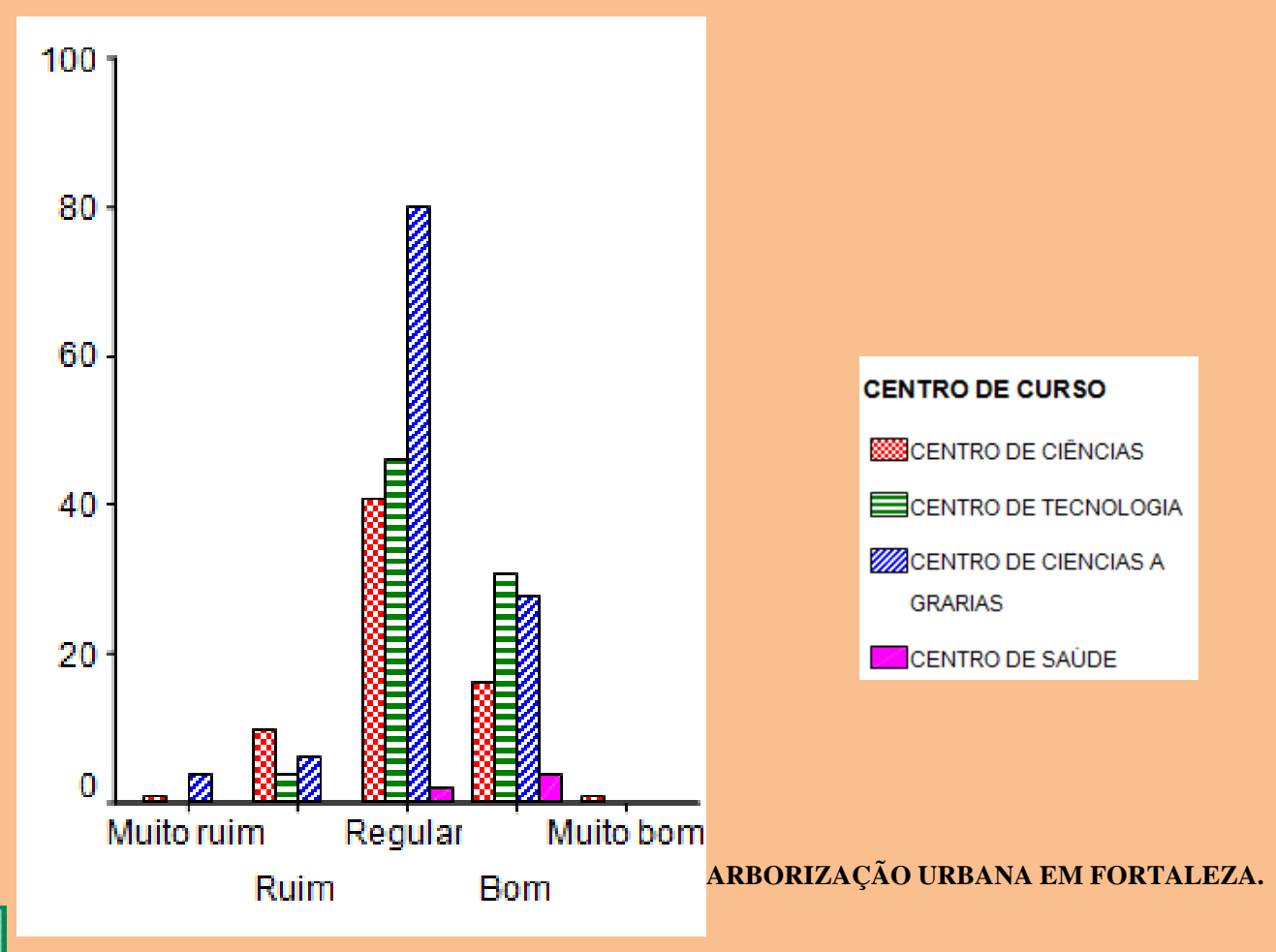


Figura 11. Representação gráfica da análise estatística da percepção da Arborização Urbana de Fortaleza versus Centro do Curso da UFC em Maio de 2007.

\section{Arborização no campus do Pici versus Centro do curso onde estuda o entrevistado}

Já quando se avaliou a relação entre o centro de Curso e a arborização no campus do Pici, a análise estatística novamente confirmou que o centro no qual o entrevistado estuda influência em sua percepção sobre a Arborização na área, e essa avaliação reflete a mudança de percepção em relação ao tamanho da área avaliada.

Por meio da Análise Estatística foi observado maior frequência de avaliações de nível muito bom para a arborização do campus do Pici pelos alunos do Centro de Tecnologia (56\%), porém essa relação se inverte quando se observa o nível bom, onde pela Análise Estatística os entrevistados, pouco mais de $50 \%$ optou por essa avaliação frequentam Centro de Ciências Agrárias, nota-se a relação entre o curso que o aluno estuda e sua opinião acerca da arborização, possivelmente devido à estrutura curricular do Curso que contempla disciplinas

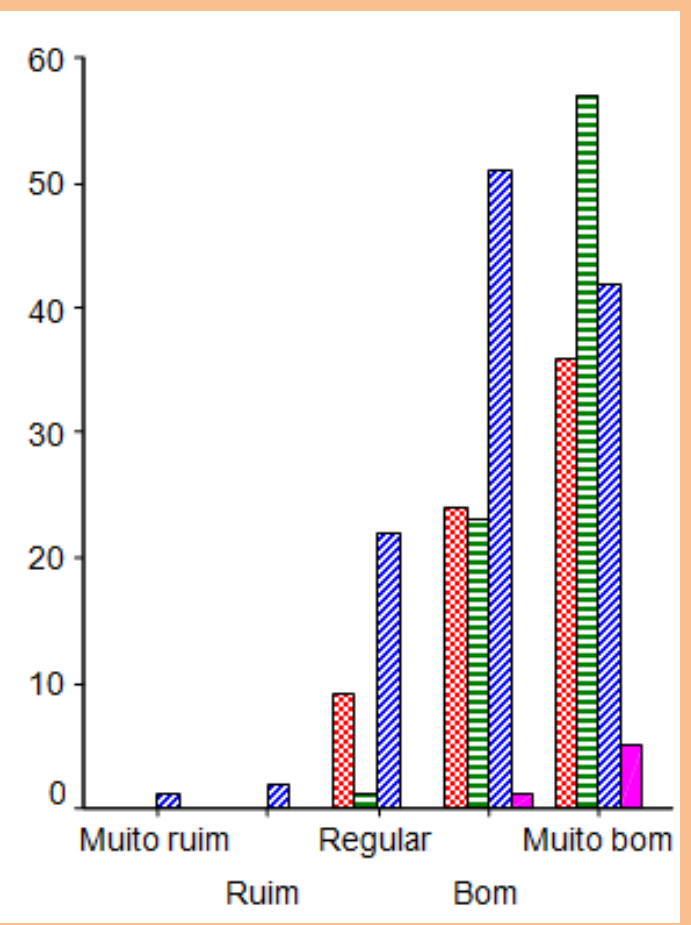

relacionadas à Arborização como paisagismo,no caso de Cursos no Centro de Ciências Agrárias, e possivelmente maior contato com espaços abertos devido à aulas práticas. Nos demais níveis de avaliação destacam-se os alunos do Centro de Ciências Agrárias, que são os únicos a mencionar os níveis muito ruim e ruim (Figura 12).

Desta forma, os resultados permitem inferir segundo os dados observados a importância da formação dos entrevistados ao considerar a importância da Arborização Urbana. Os cursos que oferecem formação mais voltada para questões ambientais e afins, provavelmente fornecem maiores subsídios para que estes entrevistados sejam mais críticos e exigentes em relação à Arborização. O teste de "qui-quadrado" para esta relação entre variáveis apresenta um nível de significância de 0,01 .

Figura 12. Representação gráfica da análise estatística da percepção da Arborização Urbana no campus do Pici x Centro do Curso da UFC em Maio de 2007.

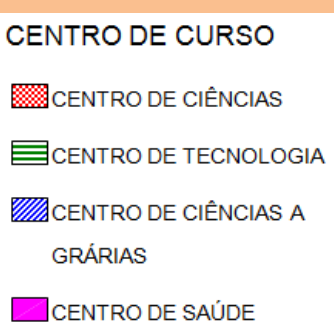

Carlos Germano Ferreira Costa et al 
Este estudo torna evidente que mesmo sem formação técnica, as pessoas têm uma opinião sobre a arborização urbana. Através desta pesquisa podese concluir que:

- a população entrevistada considera a arborização urbana de Fortaleza num nível regular;

- falhas pontuais na arborização, são avaliadas de modo mais preciso e crítico em escalas urbanas menores, de maior domínio do entrevistado;

- há forte aprovação da arborização no campi do Pici, entre a população entrevistada os resultados refletiram diferenças quando considerada a formação dos estudantes entrevistados;

- os indivíduos entrevistados apresentam maior facilidade em associar aspectos negativos à Arborização Urbana que à aspectos positivos.

- A maioria dos entrevistados afirma interesse em participar de atividades voluntárias de plantio e manutenção de árvores em áreas públicas em Fortaleza

\section{REFERÊNCIAS BIBLIOGRÁFICAS}

DANTAS, I.C.; de SOUZA, C.M.C. Arborização urbana na cidade de Campina Grande-PB: Inventário e suas espécies. Revista de Biologia e Ciências da Terra. V. 4, n.2.2004.

IBGE - Instituto Brasileiro de Geografia e Estatística. Urbanização. Em: $<$ http://www.ibge.gov.br> Acesso em 05/07/2013.

IPECE - Instituto de Pesquisa e Estratégia Econômica do Ceará. Secretarias Regionais no município de Fortaleza. em: <http://www.ipece.ce.gov.br/>. Acesso em 05/07/2013.

FUNCEME - Fundação Cearense de Meteorologia e Recursos Hídricos. Clima. Em: <http://www.funceme.br/> Acesso em 05/07/2013.

GRAZIANO, T. T. Viveiros Municipais. Departamento de Horticultura - FCAVJ - UNESP. Notas de Aula, 1994.

MALAVASI, U.C.; MALAVASI, M.M. Avaliação da arborização urbana pelso residentes-Estudo de caso em Mal. Cândico Rondon, Paraná. Ciência Florestal, Santa Maria, v.11, n.1, p.189-193,2001. 
MARQUES, V. B. Árvores nativas e exóticas usadas como ornamentais no campus do Pici - CCA-UFC. Trabalho de Conclusão de Curso (Graduação) apresentada para aprovação na Disciplina Atividade Supervisionada. Departamento de Fitotecnia, Universidade Federal do Ceará, Fortaleza, 2005.

MORO M. F., WESTERKAMP. C. The alien street trees of Fortaleza (NE Brazil): qualitative observations and the inventory of two districts. Ciência Florestal, Santa Maria, v. 21, n. 4, p. 789-798.2011.

OKAMOTO, J. Percepção ambiental e comportamento. São Paulo: Mackenzie, 2002.

OLIVEIRA, R.F. de. De urbis arboreto: o espaço primitivo interpretado. In SEMINÁRIO DE ARBORIZAÇÃO URBANA NO RIO DE JANEIRO, 1., 1996, Rio de Janeiro. Anais... Rio de Janeiro: UFRJ, p $33-44.1996$.

PONTE, S. R. Fortaleza Belle Époque: reformas urbanas e controle social (1860-1930). 3. ed. Fortaleza: Fundação Demócrito Rocha, 2001. 208p.

SANCHOTENE,M.C.C. Frutíferas Nativas úteis à fauna na arborização urbana. Porto Alegre:Sagra. 1989. $306 \mathrm{p}$.

Desenvolvimento e perspectivas da arborização urbana no Brasil. In: CONGRESSO BRASILEIRO DE ARBORIZAÇÃO URBANA, 2., 1994, São Luís. Anais... São Luís: Sociedade Brasileira de Arborização Urbana, 1994.p.15-26.

SANTIAGO, C. A. Arborização das Cidades. Boletim Técnico. Campinas: nº. 90. 1980.

SANTOS, N.R.Z.;TEIXEIRA, I.F. Arborização de Vias Públicas: Ambiente x Vegetação._Instituto Souza Cruz, $1^{\text {a }}$ ed. Porto Alegre: Ed. Pallotti. 2001. 135p.

SEUMA - Secretaria de Urbanismo e Meio Ambiente. Plano de Urbanismo, Meio Ambiente e Controle Urbano para Fortaleza. Em: <http://www.fortaleza.ce.gov.br/> Acesso em: 05/07/2013.

UFC. UNIVERSIDADE FEDERAL DO CEARÁ. Em: <http://www.ufc.br/>. Acesso em 05/07/2013. 